\title{
Self-management and psychological-sexological interventions in patients with endometriosis: strategies, outcomes, and integration into clinical care
}

\author{
This article was published in the following Dove Press journal: \\ International Journal of Women's Health \\ 2 May 2017 \\ Number of times this article has been viewed
}

\author{
Laura Buggio 1,2 \\ Giussy Barbara ${ }^{3}$ \\ Federica Facchin ${ }^{4}$ \\ Maria Pina Frattaruolo 1,2 \\ Giorgio Aimi² \\ Nicola Berlanda ${ }^{2}$ \\ 'Department of Clinical Sciences \\ and Community Health, Università \\ degli Studi di Milano, ${ }^{2}$ Departmental \\ Operating Unit of Surgical \\ Gynecology and Endometriosis, \\ Fondazione Istituto di Ricovero e \\ Cura a Carattere Scientifico Ca' \\ Granda Ospedale Maggiore Policlinico, \\ ${ }^{3}$ Department of Obstetrics and \\ Gynecology and Service for Sexual \\ and Domestic Violence (SVSeD), \\ Fondazione Istituto di Ricovero e \\ Cura a Carattere Scientifico Ca' \\ Granda, Ospedale Maggiore \\ Policlinico, ${ }^{4}$ Faculty of Psychology, \\ Catholic University of Milan, Milan, \\ Italy
}

\begin{abstract}
Endometriosis has a multifactorial etiology. The onset and progression of the disease are believed to be related to different pathogenic mechanisms. Among them, the environment and lifestyle may play significant roles. Diet, dietary supplements, physical exercise, osteopathy, massage, acupuncture, transcutaneous electrical nerve stimulation, and Chinese herbal medicine may represent a complementary and feasible approach in the treatment of symptoms related to the disease. In this narrative review, we aimed to examine the most updated evidence on these alternative approaches implicated in the self-management of the disease. In addition, several studies have demonstrated that endometriosis may negatively impact mental health and quality of life, suggesting that affected women may have an increased risk of developing psychological suffering as well as sexual problems due to the presence of pain. In light of these findings, we discuss the importance of integrating psychological interventions (including psychotherapy) and sexual therapy in endometriosis treatment.
\end{abstract}

Keywords: sexual therapy, diet, physical activity, alternative medicine, psychotherapy

\section{Introduction}

Endometriosis is a hormone-dependent, chronic inflammatory condition associated with pelvic pain symptoms and infertility. ${ }^{1-3}$ About $5 \%$ of women of reproductive age suffer from the disease. ${ }^{4}$ The etiology of this condition has been only partly clarified; numerous pathogenic factors, like lifestyle and environmental ones, have been claimed to be involved in the onset, maintenance, and progression of the disease. ${ }^{5}$

Although hormonal therapies represent the cornerstone in the management of endometriosis, ${ }^{1,4}$ the possible adjuvant role of other remedies and behaviors, such as diet, dietary supplements, physical exercise, osteopathy, acupuncture, and Chinese herbal medicine (CHM), could represent a complementary and feasible approach in the treatment of symptoms related to the disease. Complementary and alternative medicine (CAM) has been used extensively in most Asian countries since the nineteenth century; however, their utilization in Western countries has been rapidly growing. ${ }^{6}$ In this narrative review, we examine the most updated evidence on these alternative factors implicated in the self-management of the disease.

Moreover, several studies have demonstrated that endometriosis, especially when symptomatic, may negatively impact mental health and quality of life (QoL), ${ }^{7}$ suggesting that affected women may have an increased risk of developing psychological 
suffering as well as sexual problems due to the presence of pain. In light of these evidences, we discuss the importance of integrating psychological interventions (including psychotherapy) and sexual therapy in endometriosis treatment.

In this review, the best-quality evidence was selected, with preference given to the most recent and definitive original articles and reviews. Information was identified by searches of Medline and references from relevant articles, using combinations of the Medical Subject Heading terms "endometriosis", "diet", "food”, "physical activity", "physical exercise", "alternative medicine", "complementary alternative medicine", "acupuncture", "osteopathic manipulative therapy", "herbal medicine", "vitamin", "n-acetylcysteine", "resveratrol", "endocrine disruptors", "psychotherapy”, "deep dyspareunia", "sexual therapy", and "sexual dysfunctions". The search was limited to articles in the English language. For most issues, papers published between December 1990 and January 2017 were considered.

\section{Diet}

In recent years, the role of diet in the pathogenesis of endometriosis has gained momentum, due to the influence of diet in several processes related to the disease, such as inflammation, prostaglandin metabolism, and estrogen activity. ${ }^{8,9}$ Moreover, in the last two decades, organochlorines, including polychlorobiphenyls and pesticides/insecticides, that can be ingested through various nutrients have been proposed as risk factors for the disease. ${ }^{10}$ In addition, the shift to a Western-style dietary pattern, characterized by a large intake of refined, processed, and canned foods, plenty of colorants, pesticides, preservatives, and stabilizers in theory may have generated an imbalance in the body, favoring a proinflammatory state and increasing circulating free radicals and oxidative stress. ${ }^{11}$ Despite these premises, the role of diet on endometriosis risk remains elusive, eg, in a systematic review of the literature by Parazzini et $\mathrm{al}^{8}$ of eleven studies, the results were characterized by extreme variability, and strong or definitive information could not be provided.

Several studies have focused on the relationship between endometriosis and fish oils/polyunsaturated fatty acids (PUFAs), because these nutrients have an anti-inflammatory profile and are able to reduce proinflammatory prostaglandin production. $\omega 3$ PUFAs can be found mostly in salmon, tuna, and halibut. A large study by Missmer et $\mathrm{al}^{9}$ on a population of 70,709 US women, 1,081 of whom with a diagnosis of endometriosis, revealed that high intake of long-chain $\omega 3$ fatty acids (FAs) and decreased consumption of trans unsaturated FAs reduced the risk of endometriosis. Instead, an increased risk was associated with animal-fat ingestion, particularly palmitic acid. ${ }^{9}$ The $\omega 3$ FA: $\omega 6$ FA ratio has been investigated in three studies. Missmer et $\mathrm{al}^{9}$ and Netsu et $\mathrm{al}^{12}$ demonstrated that a higher ratio reduced the risk of the disease; on the contrary, Khanaki et al ${ }^{13}$ found a positive correlation between the ratio and the severity of the disease. Savaris and do Amaral ${ }^{14}$ reported a lower consumption of PUFAs in women affected by the disease, resulting in an imbalanced formation of long-chain $\omega 3$ PUFAs. In an endometriosis rat model, Netsu et $\mathrm{al}^{12}$ found a significant reduction in the thickening of the active site for inflammation in endometriosis in rats fed with a diet supplemented with $\omega 3$ eicosapentaenoic acid. On the other hand, three other studies, ${ }^{15-17}$ did not reveal a significant association between intake of fish or other dietary fats and risk of endometriosis.

The relationship between red meat and risk of endometriosis has been analyzed in three studies. An Italian case-control study ${ }^{17}$ found a significantly higher risk of the disease in women reporting higher meat and ham intake. A plausible explanation of the role of red meat in the pathogenesis of the disease could be represented by the high amount of fat contained in this nutrient, in particular $\omega 6 \mathrm{FAs}$, implicated in the production of proinflammatory prostaglandins. However, this association was not replicated in other studies by Trabert et $a l^{16}$ or Heilier et al. ${ }^{15}$

Two studies have investigated the relation between fruit and vegetable consumption and endometriosis risk. ${ }^{16,17}$ Parazzini et $\mathrm{al}^{17}$ found that intake of both these nutrients led to decreased risk; on the contrary, in the case-control study conducted by Trabert et $\mathrm{al}^{16}$ an increased number of servings/day of fruit was associated with an augmented risk of the disease, but no association appeared with vegetables. These results could be explained by the fact that nowadays the cultivation of fruit involves extensive use of pesticides and dioxins, both implicated in the production of reactive oxygen species, as well as in the reduction of the antioxidant properties of these categories of food.

In order to evaluate the potential association between coffee/caffeine intake, Chiaffarino et $\mathrm{al}^{18}$ recently conducted a meta-analysis. Eight studies were included, six case-control and two cohort studies, with 1,047 endometriosis patients in total. The meta-analysis provided no evidence for an association between coffee/caffeine ingestion and risk of the disease. The consumption of caffeine has been extensively analyzed, due to its property to act on hepatic production of sex hormone binding globulin (SHBG), reducing testosterone bioavailability, ${ }^{19,20}$ as well as for its role in inhibiting aromatase, an enzyme involved in the conversion of androgens to estrogens. ${ }^{21}$ 
The role of a gluten-free diet in the management of symptomatic endometriosis has also been evaluated in two Italian retrospective studies. ${ }^{22,23}$ The rationale of these studies was the potential proinflammatory role of gluten that could enhance the production of specific cytokines involved in the exacerbation of the disease. Both studies demonstrated an improvement in pain symptoms in women who followed a gluten-free diet. The possible role of gluten in the worsening of the disease is indeed intriguing; however, due to the scanty available evidence on this topic, further research is needed in order to confirm this hypothesis.

\section{Physical activity}

Physical activity has been identified as a possible modifiable, protective factor for endometriosis. In fact, the protective effects of regular physical activity have been previously demonstrated in the treatment of other disorders involving inflammatory processes, such as type 2 diabetes mellitus, inflammatory bowel disease, and colon and breast cancer. ${ }^{24-26}$

With regard to endometriosis, various etiopathogenic assumptions may contribute to explain why physical activity may be a protective factor. First, exercise may reduce estrogen levels and frequency of ovulation when performed at high levels of intensity;27 second, physical activity may increase SHBG levels, which would decrease bioavailable estrogens. ${ }^{28-30}$ Moreover, regular physical activity also reduces insulin resistance and hyperinsulinemia, ${ }^{28}$ which has been hypothesized to be associated with endometriosis. In addition, regular exercise leads to an increase in the systemic levels of cytokines with anti-inflammatory properties. ${ }^{29,30}$

Recently, Ricci et $\mathrm{al}^{27}$ performed a systematic review and meta-analysis of the literature to clarify the potential association between endometriosis and physical activity. The meta-analysis combined data from nine studies - six case-control studies and three cohort studies - involving 3,355 cases for recent physical activity and 4,600 case for past physical activity. The summary odds ratio for endometriosis for any recent versus no physical activity was 0.85 (95\% confidence interval [CI] 0.67-1.07). Compared to no recent physical activity, odds ratios for low and moderate/high exercise were 1 (95\% CI $0.68-1.28)$ and 0.75 (95\% CI 0.53-1.07), respectively. The authors concluded that although physical activity may reduce the risk of the disease, the meta-analysis had not provided definitive support to this hypothesis.

The possible anti-inflammatory effect of physical activity has also been evaluated in a rat model. Rosa-e-Silva et $\mathrm{al}^{31}$ divided 70 female rats with experimentally induced endometriosis in seven groups of ten animals each: sedentary-, light-, moderate-, and intense-exercise programs. Endometriosis was induced before physical activity in three groups and after disease induction in the other three. A reduction in levels of oxidative stress, MMP9, and proliferating cell nuclear antigen (PCNA) was identified in all the groups that practiced physical exercise, indicating a reduction in proliferation, migration, and differentiation of endometriotic tissue.

Recently, the practice of yoga has gained worldwide spread, due to its ability to integrate the body and mind through a balanced mixture of contemplative techniques that are able to reduce stress and, at the same time, strengthen musculature. ${ }^{32}$ As stated by the World Health Organization, yoga has been classified as a mind-body practice $^{33}$ that improves symptoms of various disorders, such as asthma and high blood pressure. ${ }^{34-36}$ Gonçalves et $\mathrm{al}^{32}$ evaluated the effects of yoga on 15 women with symptomatic endometriosis. All patients attended yoga practice twice a week for 8 weeks, and at the end of the program all participants reported a beneficial effect of yoga in pelvic pain management. In addition, women stated that through the practice of yoga, they developed self-control and selfawareness, with improved self-care and self-esteem. In conclusion, through the learning of specific postures and breathing and meditation techniques, yoga improved the ability of patients experiencing pain to control their symptoms. Further research is needed to confirm these promising preliminary and uncontrolled results.

\section{Complementary and alternative medicine}

As stated by the World Health Organization, ${ }^{37}$ CAM comprises a range of different health-related strategies that can be defined as predominantly operating outside the conventional medical curriculum and profession. The list of CAMs includes several procedures and products that have been tested in the treatment of women with endometriosis, such as osteopathic manipulative therapy (OMT), massages, acupuncture, transcutaneous electrical nerve stimulation (TENS), CHM, vitamins, and dietary supplementations.

Symptomatic women with endometriosis represent a large catchment area for CAM. In fact, as reported by Fisher et al,,$^{38}$ patients affected were significantly more likely to consult a CAM practitioner or use CAM products compared to women without the disease. In this article, we review the main evidence on the use of different CAM in women with endometriosis. 


\section{Osteopathic manipulative therapy and massage}

Osteopathy is characterized by manipulative techniques, and can be defined as a drug-free manual medicine that adopts manipulations to treat somatic dysfunctions. ${ }^{39}$ OMT has been successfully used in the treatment of chronic back pain. ${ }^{40,41}$ The principle on which this practice is based is that inflammation of internal organs can provoke musculoskeletal symptoms and vice versa. ${ }^{42}$ Two studies have analyzed the impact of OMT on women with endometriosis. Darai et $\mathrm{al}^{43}$ evaluated the role of OMT on the QoL of patients with deep infiltrating endometriosis and colorectal involvement. A total of 20 patients were recruited, of whom 15 (75\%) completed the study protocol. A significant improvement in most items of the Short Form-36 (SF-36) questionnaire was observed, with an overall success rate of $80 \%$ (12 of 15 patients). A recent German study ${ }^{42}$ investigated the efficacy of OMT on 28 women with chronic pelvic pain, including 14 with a previous diagnosis of endometriosis. The treatment was completed by 22 patients, 17 of whom reported an improvement in pain symptoms. In the subcategory of women with endometriosis, ten of 14 reported amelioration of the symptoms. Both these studies provide encouraging results to consider OMT a valuable additional treatment in the management of women with endometriosis. However, poor research design, paucity of data, small samples sizes, and limited study periods represent major sources of bias.

With regard to the potentially adjuvant role of bodymassage therapy in the treatment of endometriosis, one Iranian study ${ }^{44}$ enrolled 23 patients with dysmenorrhea and a surgically confirmed diagnosis of endometriosis. A statistically significant improvement in pain intensity was described immediately after the beginning of the massages, as well as at 6-week follow-up. Further studies are needed to determine the real role of OMT and massage therapy as part of a multimodal approach to the treatment of symptomatic endometriosis.

\section{Acupuncture and TENS}

Acupuncture is a therapeutic technique characterized by the insertion of fine metallic needles into or through the skin at specific sites. ${ }^{45}$ This practice has been shown to have the potential to interfere with pain pathways with different mechanisms. First, acupuncture could induce the release of endogenous opioids in brain-stem, subcortical, and limbic structures. Second, in a mouse model, electroacupuncture stimulated pituitary production of cortisol and adrenocorticotropic hormone, facilitating an anti-inflammatory systemic effect. ${ }^{45}$ In addition, human studies have shown beneficial effects of prolonged acupuncture treatment in the deactivation of brain areas linked to the transmission of pain sensations. ${ }^{45,46}$ Finally, acupuncture induces local effects, such as mechanical stimulation of connective tissue, release of adenosine at the needle-insertion site, and intensification of local blood flow..$^{45}$

Due to its pain-alleviating effects, acupuncture is widely used in the treatment of different conditions. ${ }^{46,47}$ Moreover, major adverse effects are rarely reported. ${ }^{45}$ However, despite the encouraging premises, a recent Cochrane meta-analysis ${ }^{48}$ that evaluated the effectiveness and safety of acupuncture and acupressure in the treatment of primary dysmenorrhea when compared with placebo, no treatment, or conventional medical treatment showed that the quality of the available evidence was low or very low for all comparisons and insufficient to demonstrate the effectiveness of this technique.

Lund and Lundeberg ${ }^{46}$ performed a meta-analysis to summarize the clinical effects of acupuncture on pelvic pain related to endometriosis. Three studies were included, with a total of 121 women with diagnosed endometriosis enrolled. One of the studies ${ }^{49}$ was a retrospective case series based on the history of two adolescent endometriosis patients treated with acupuncture. Also in Wayne et al, ${ }^{50}$ only adolescent women with endometriosis were enrolled. In this study, the authors performed a particular Japanesestyle acupuncture technique that differed from the traditional Chinese technique for the use of smaller needles and shallower insertion sites, making this method less invasive and better received by an adolescent population. In all studies, acupuncture had beneficial effects on pain intensity. In addition, patients reported an increase in social activities and school attendance in one study ${ }^{49}$ and an improvement in health-related QoL in the other two studies. ${ }^{50,51}$ None of the studies reported side effects. The overall results of the effects of acupuncture on pelvic pain related to endometriosis seem encouraging, particularly among adolescent women. However, no definitive conclusions can be drawn from these studies, due to the small sample sizes.

TENS is a non-invasive and low-cost technique based on the use of mild electrical impulses applied to the intact surface of the skin with the objective of stimulating lowthreshold nerves to relieve pain and favor the release of endogenous opioids. ${ }^{52,53}$ Based on a review of Proctor et al ${ }^{54}$ on dysmenorrhea in general, TENS has been mentioned as alternative short-term pain management in women with 
dysmenorrhea in a consensus document on the management of endometriosis. ${ }^{55}$

Only one randomized controlled trial has investigated the role of TENS as complementary pain treatment in women with endometriosis. Mira et $\mathrm{al}^{53}$ evaluated the effectiveness of TENS on persistent pelvic pain, dyspareunia, and QoL in symptomatic women with deep endometriosis. They enrolled 22 patients and randomized them into two groups: acupuncture-like TENS $(n=11)$ and self-applied TENS $(\mathrm{n}=11)$. In both groups, TENS was applied for 8 weeks at the S3-S4 region. For all participants, TENS provided pain relief, with statistically significant improvement in pelvic pain, deep dyspareunia, and dyschezia; for the latter type of pain, relief was observed only with the application of acupuncture-like TENS. No improvement was registered for dysmenorrhea or dysuria. QoL was evaluated through the Endometriosis Health Profile questionnaire; after treatment, total scores were significantly reduced, indicating an amelioration of QoL. Finally, patients reported an improvement in emotional well-being, social support, and self-image. Acupuncture and TENS could represent alternative options in patients with symptomatic endometriosis resistant to hormonal therapy. However, the evidence is still scarce, and further larger studies are needed to confirm these promising preliminary results.

\section{Chinese herbal medicine}

CHM comprises the use of herbal formulae of different herbal ingredients (10-20) chosen from a materia medica of several hundred common herbs that are prepared as boiled decoctions, dried extracts, or pills. ${ }^{6}$ These compounds could be administered either orally, through enema, or an intramuscular route. In China, herbal medicine (HM) is widely applied, and is considered a routine treatment in patients with endometriosis, due to its theoretical ability to reduce pain, prevent recurrence, and enhance fertility. At the basis of HM efficacy, there would be the potential anti-inflammatory activity on endometrial cells. Moreover, its use on animal models has shown its ability to suppress endometriotic implants. ${ }^{56,57}$

Flower et $\mathrm{al}^{58}$ conducted a Cochrane review to clarify the effectiveness and safety of CHM in relieving endometriosisrelated pain and infertility. Two Chinese randomized control trials were included, ${ }^{59,60}$ with a total of 158 patients enrolled. Both studies were of limited quality. One study compared the postsurgical administration of CHM (oral plus enema) to gestrinone, with comparable benefits on pain and pregnancy rates. ${ }^{59}$ In the other study, women were divided in three groups: oral CHM, oral plus enema CHM, or danazol. Oral plus enema administration resulted in greater reduction in dysmenorrhea-pain scores than danazol, whereas no differences were reported regarding vaginal nodule tenderness, lumbosacral pain, or dyschezia. ${ }^{60}$ In both studies, there were fewer side effects with CHM. However, as stated by Flower et al, “... more rigorous research is required to accurately assess the potential role of CHM in treating endometriosis" ${ }^{58}$ In addition, the authors adopted inadequate comparison treatments. In fact, danazol and gestrinone are no longer used as conventional and first-line treatment for endometriosis. For these reasons, a control group of women using estroprogestins or progestins, which are nowadays considered the first-line medical treatments of endometriosis, would have been advisable.

Zhu et $\mathrm{al}^{61}$ conducted a prospective randomized study comparing laparoscopy alone with laparoscopy followed by treatment with oral contraceptives (OCs) or a combination of OCs and the Dan'e mixture, a Chinese herbal combination that has similar properties to danazol. The OC was administered continuously for 63 days after surgery, while $\mathrm{HM}$ was added at a dosage of $30 \mathrm{~g}$ /day for the latter 30 days. Only infertile patients with minimal/mild endometriosis were enrolled. A total of 156 patients were randomized into the three study groups. The primary outcome of the study was pregnancy rate and live-birth rate. Follow-up lasted 12 and 14 months in women who had undergone laparoscopy alone and in those who had received medical treatment after surgery, respectively. Differences in pain scores were also evaluated. No significant differences were observed among the three groups regarding pregnancy rate or live-birth rate. Women under medical therapy (OCs alone or OCs plus HM) had lower pain scores compared with the laparoscopy-alone group; no difference in pain scores was identified between the two medical treatment groups. In conclusion, the addition of the herbal mixture did not provide any advantage in terms of enhancing fertility or in terms of pain reduction.

\section{Vitamins and dietary supplements}

Vitamins are organic compounds and vital nutrients that an organism requires in limited amounts. ${ }^{62}$ In the endometriosis field, one of the most studied vitamins is certainly vitamin $\mathrm{D}$, due to its antiproliferative, anti-inflammatory, and immunomodulatory properties. ${ }^{63}$ Moreover, vitamin D receptor is expressed in ovarian tissue, endometrium, and fallopian epithelial cells. ${ }^{63}$ Lasco et al ${ }^{64}$ evaluated the effect of a single dose of $300,000 \mathrm{IU}$ of cholecalciferol (vitamin $\mathrm{D}_{3}$ ) 
for treatment of primary dysmenorrhea, demonstrating a significant decrease in pain in the supplemented group. Moreover, a selective vitamin D-receptor agonist, elocalcitol, has been shown to diminish endometriosis development in a murine model. ${ }^{65}$ Recently, Miyashita et $\mathrm{al}^{66}$ performed an in vitro study to assess the effects of 1,25-dihydroxyvitamin $\mathrm{D}_{3}\left(1,25[\mathrm{OH}]_{2} \mathrm{D}_{3}\right)$ on human endometriotic stromal cells: $1,25(\mathrm{OH})_{2} \mathrm{D}_{3}$ significantly reduced the levels of inflammatory mediators, such as IL1 $\beta$, IL8, prostaglandin activity, MMP2, and MMP9, and decreased endometriotic stromal cell numbers and DNA synthesis. On the contrary, a recent double-blind clinical trial ${ }^{67}$ on 39 patients with surgical diagnosed endometriosis investigating the effect of vitamin D supplementation on pelvic pain did not find any significant difference between supplemented women and a placebo group. In the last two decades, various clinical trials have evaluated the relationship between endometriosis and vitamin D serum levels, with contradictory results (Table 1). Finally, Ciavattini et al ${ }^{72}$ assessed vitamin D serum levels in a cohort of 49 patients with ovarian endometrioma, showing deficient vitamin D levels in about $85 \%$ of the study population. In addition, a significant linear correlation between 25-hydroxyvitamin D (25(OH)D) serum levels and the diameter of the cyst emerged.

Other compounds that could play a role in the pathogenesis of endometriosis are vitamin $\mathrm{A}$, vitamin $\mathrm{C}$, and $\beta$-carotene, due to their antioxidant activity. In fact, oxidative stress may exert a central role in the development and progression of the disease through an intensification of growth and adhesion of endometrial cells in the peritoneal cavity. ${ }^{57}$ Mier-Cabrera et $\mathrm{al}^{73}$ discovered low concentrations of vitamin $\mathrm{C}$ in the peritoneal fluid of women with endometriosis, and demonstrated an imbalance between antioxidant and oxidant markers in favor of the latter. However, a 6-month specific antioxidant diet enriched with vitamins (A, B $, C, E)$, lactic ferments, mineral salts, and $\omega 3$ and $\omega 6$ FAs had no impact on the recurrence rate of endometrioma when compared with laparoscopy plus placebo. ${ }^{74}$

$N$-acetylcysteine (NAC) is a nutritional supplement that acts as a direct precursor to glutathione synthesis, and has been successfully used for a wide range of metabolic disorders, pulmonary diseases, hepatotoxicity, and immunotoxicity. ${ }^{75}$ NAC could reduce the release of inflammatory cytokines and is able to interfere the inflammation cascade process controlled by NF $\kappa \mathrm{B}$ activity. ${ }^{75} \mathrm{NAC}$ acts through the activation of numerous molecular mechanisms, all converging into a proliferation-to-differentiation switch that brings a reduction in cell proliferation and downregulation of the inflammatory cascade. ${ }^{76}$ Food sources of NAC include garlic, broccoli, red pepper, onion, and animal protein, in particular such meats as pork, chicken, turkey, and duck. ${ }^{77}$ In an Italian case-control study, ${ }^{76}$ women supplemented with NAC (600 mg three times a day for 3 days a week for 3 months versus placebo) showed a reduction in mean endometrioma diameter and an improvement in dysmenorrhea, dyspareunia, and chronic pelvic pain, without reporting any adverse reactions. Pittaluga et $\mathrm{al}^{78}$ explored NAC action in vivo by using a mouse model of endometriosis, demonstrating a significant reduction in endometrioma weight in the treated group compared with the control group.

Resveratrol (trans-3.4',5-trihydroxystilbene) is a phytoalexin polyphenol produced by some grape species, berries, and nuts in response to ultraviolet radiation or fungal infections. ${ }^{79}$ Significant concentration of this compound could be find in red wine, thanks to the high concentration of resveratrol in the skin of grapes. Several studies have demonstrated the antiangiogenic, anti-inflammatory, and antioxidant properties of resveratrol, which has been found to be beneficial for multiple diseases, such as cancer and cardiovascular diseases. ${ }^{80,81}$ In the first study evaluating the effects of resveratrol on endometriosis lesions, ${ }^{82}$ daily oral gavage of resveratrol significantly diminished the number and size of

Table I Relationship between endometriosis and 25(OH)D serum levels (literature data 1990-2016)

\begin{tabular}{|c|c|c|c|}
\hline Study & Country & Number of patients enrolled & 25(OH)D serum levels \\
\hline Hartwell et al ${ }^{68}$ & Denmark & 42 & Normal \\
\hline Somigliana et $\mathrm{a}^{69}$ & Italy & 140 (endometriosis, $n=87$; controls, $n=53$ ) & Increased \\
\hline Agic et $\mathrm{al}^{70}$ & Germany & 79 (endometriosis, $n=46$; controls, $n=33$ ) & Normal \\
\hline Harris et $\mathrm{al}^{71}$ & US & 70.556 (endometriosis, $n=1,385$; controls $n=69,171$ ) & Decreased \\
\hline Miyashita et al ${ }^{66}$ & Japan & 76 (endometriosis $n=39 ;{ }^{a}$ controls $n=37$ ) & Decreased $^{b}$ \\
\hline Ciavattini et $\mathrm{al}^{72}$ & Italy & $49^{c}$ & Decreased \\
\hline
\end{tabular}

Notes: Mild endometriosis ( $n=17$, stages I and 2), severe endometriosis ( $n=22$; stages 3 and 4); bserum levels of $25(\mathrm{OH}) \mathrm{D}$ in samples from patients with severe endometriosis were significantly lower than the levels detected in samples from the controls and the patients with mild endometriosis; 'only patients with singleton endometrioma were included.

Abbreviation: $25(\mathrm{OH}) \mathrm{D}, 25$-hydroxyvitamin D. 
endometriotic lesions in mouse models. These preliminary results have been confirmed by two other studies. ${ }^{83,84}$ In both studies, performed on mouse models, resveratrol significantly reduced the number and volume of the endometriotic lesions, through a reduction in cell proliferation, vascular density, and favoring apoptosis. In addition, another experimental study compared the effects of resveratrol alone and in combination with leuprolide acetate, a gonadotropin-releasing hormone analog. ${ }^{85}$ The authors found that resveratrol was as effective as leuprolide acetate in endometriosis management when used alone; on the other hand, the combination of resveratrol and leuprolide acetate did not show any beneficial additive effect.

One of the major sources of resveratrol is red wine; however, long-term consumption of this beverage is not recommended, due to the alcohol content; other food products should be contemplated as a different source of resveratrol, as well as compressed pills with the necessary dose. ${ }^{83}$ Moreover, further studies on human subjects are needed, in order to clarify the real effectiveness of this polyphenol and the needed dosage to achieve inhibition of endometriotic cell growth.

\section{Endocrine disruptors}

Endocrine-disrupting chemicals (EDCs) include any exogenous chemical or mixture of chemical substances that can interfere with any aspect of hormonal action. ${ }^{86}$ With regard to endometriosis, experimental research and studies on primates have posed questions on a possible role of these chemicals in the pathogenesis of the disease.$^{87}$ EDCs could be involved in the pathogenesis of endometriosis due to their ability in altering hormone synthesis, modulating receptors, or acting as agonists or antagonists. ${ }^{87}$

In particular, dioxin and dioxin-like compounds represent one of the most studied substances. ${ }^{88}$ These lipophilic substances are ubiquitous environment pollutants that mainly enter into the human body through food and accumulate in tissue with high-fat content. ${ }^{89}$ In a study on rhesus monkeys, a dose-dependent relation was observed between 2,3,7,8-tetrachlorodibenzo- $p$-dioxin (TCDD) and dioxin-like polychlorinated biphenyls (PCBs) and peritoneal endometriosis. ${ }^{90,91}$ It has been hypothesized that TCDD may provoke the proliferation of endometrial cells that are significant for endometrial angiogenesis. ${ }^{92}$ These results were not confirmed in a large epidemiological study, ${ }^{93}$ which did not demonstrate any increased incidence of the disease in women living in Seveso, Italy, where in 1976 there was a factory explosion. The authors reported a doubled, nonsignificant risk for endometriosis among women with serum TCDD levels of 100 parts per trillion or higher, but no clear dose response. On the contrary, Heilier et al ${ }^{94}$ demonstrated increased serum levels of dioxin-like compounds in women with endometriosis, in particular in those with deep endometriotic nodules. The potential implication of environmental organochlorinated persistent pollutants, especially dioxins and PCBs, on endometriosis has been evaluated in an Italian case-control study. ${ }^{95}$ The authors showed an association between increased PCBs and 1,1-dichloro-2,2bis(4-chlorophenyl)ethene ( $p, p$ '-DDE) serum levels and the risk of endometriosis.

Another extensively studied compound is bisphenol (BP) A, a substance widely used in the manufacture of plastics. BPA has estrogenic properties and can bind in vitro and in vivo to $\alpha$ - and to a lesser degree $\beta$-estrogen receptors; ${ }^{96}$ consequently, BPA could be involved in the occurrence of estrogen-dependent diseases, such as endometriosis. ${ }^{97}$ In addition, a possible adverse effect of BPA on fertility has been suggested. ${ }^{98,99}$ In particular, Caserta et al $^{99}$ demonstrated that women with high concentrations of BPA were significantly more frequently infertile than those with normal BPA levels. Cobellis et $\mathrm{al}^{100}$ measured the levels of BPA and BPB in the blood serum of 58 women with endometriosis and eleven healthy controls. The two BPs were not detected in any of the control sera, whereas it was measured in $63.8 \%$ of the samples derived from endometriotic patients. On the contrary, two studies evaluating urinary BPA concentrations did not observe any association with the disease. ${ }^{101,102}$ Finally, Signorile et al $^{103}$ demonstrated in a mouse model that offspring of animals exposed to BPA during pregnancy developed endometriosis-like structures significantly more frequently than controls. More data are needed, in order to disentangle these conflicting results and assess the relationship between EDCs and endometriosis.

\section{Psychological interventions}

A growing number of quantitative and qualitative studies have shown that endometriosis may have a negative impact on women's psychological health and health-related QoL. Some of these works focused on endometriosis itself as a gynecological chronic disease often associated with anxiety and depression due to prognostic uncertainty and threat of infertility (as well as ascertained infertility). ${ }^{104,105}$ Other studies focused on endometriosis-related pelvic pain, emphasizing how having versus not having pelvic pain (especially chronic pelvic pain) may lead to different psychological 
outcomes. ${ }^{7}$ Despite the increasing amount of evidence, research examining the efficacy of psychological interventions (including psychotherapy) with endometriosis patients is still scarce.

In a recent study, Meissner et al ${ }^{106}$ investigated whether psychotherapy with somatosensory stimulation (ie, different acupuncture-point stimulation techniques) could lead to improved QoL and pelvic pain in 67 endometriosis patients randomly assigned to the intervention $(n=35)$ or to a waiting list ( $\mathrm{n}=32$ ). Not only did this type of intervention lead to significant improvement in global pain, physical and mental QoL at 3-month follow-up but also these positive changes remained stable at 6 and 24 months after the intervention, when all participants (including those assigned to the waiting list) had been treated.

Hansen et al ${ }^{107}$ reported long-term effects (6-year follow-up) of a ten-session mindfulness-based psychological intervention (both individual and group sessions). The overall intervention involved ten women with endometriosis-related chronic pelvic pain, and comprised mindfulness training, visualization techniques, counseling, group support, and patient education with a specific focus on fatigue, quality of sleep, job, relationships, and family issues. Women showed a global long-lasting improvement on health-related QoL, with no decline when findings were compared with those derived from a first assessment at 12 months after the intervention. ${ }^{108}$

Overall, the extant endometriosis literature reports short- and long-term outcomes of psychological interventions focused mainly on endometriosis-related symptoms and especially on pelvic pain, which indeed represents a major clinical problem in women with the disease. There is evidence that chronic pelvic pain negatively affects mental health, but recent qualitative research ${ }^{109}$ has shown that endometriosis might have a negative pervasive impact on women's psychological health for reasons other than pelvic pain. For instance, the disruption caused by the disease and the inability to restore a sense of biographical continuity is an important source of anxiety and depression. ${ }^{110}$ This growing body of knowledge, which also suggests the extent to which women's sense of female identity can be negatively affected by endometriosis, indicates that psychological interventions with distressed endometriosis patients should not be exclusively focused on pain symptoms; a proper psychotherapeutic intervention aimed at helping women integrate endometriosis into their own history should be encouraged. However, there is no research systematically exploring the effectiveness of psychotherapy (either cognitive behavioral or psychodynamic therapy) in women with endometriosis. Overall, based on our clinical practice and previous research, ${ }^{7,110,111}$ we suggest that women may benefit from supportive-expressive psychotherapeutic interventions (either individual or group interventions) aimed at facilitating the expression of deepest thoughts and feelings about endometriosis, as well as at empowering their female identity. Adequately designed trials are needed to define the magnitude of the benefit of psychotherapeutic interventions in different clinical conditions.

\section{Sexological interventions}

A consistent percentage of women with endometriosis (about 60\%-70\%) suffer from some form of sexual dysfunction. ${ }^{112}$ In particular, endometriosis is associated with an increased risk of deep dyspareunia, with potentially negative effects on global female sexual functioning, intimate and couple relationships, psychological well-being, and QoL. ${ }^{112}$

Typically, deep dyspareunia is related to deep infiltrating endometriosis, characterized by the presence of endometriotic lesions infiltrating the posterior vaginal fornix, the pouch of Douglas, the uterosacral ligaments, the bladder, or the rectum. In these cases, it is plausible that pain during intercourse is predominantly elicited by mechanical pressure on lesions occurring during coitus, or by traction of inelastic and scarred endometriotic tissue. ${ }^{113,114}$ In patients with other forms of endometriosis, pain during intercourse can also be triggered by a condition of severe pelvic inflammation. Moreover, women with endometriosis under hormonal therapy may also experience dyspareunia due to vaginal dryness caused by the treatment itself.

However, dyspareunia is not the only sexual complaint in women suffering from endometriosis. Several studies have shown that pain during intercourse is commonly associated with a broad range of different sexual dysfunctions, such as hypoactive sexual desire, lubrication, arousal, and orgasm disorders. All these sexual dysfunctions frequently coexist, and may result in poor global female sexual satisfaction and couple disagreement. ${ }^{115-117}$ The vicious circle of perpetration of sexual dysfunction in women with endometriosis commonly starts with the presence of recurrent dyspareunia, and the consequent fear and anticipation of pain at every attempt at sexual intimacy. Sexual response is a multifaceted and complex phenomenon, which requires physiological and mental activation to erotic stimuli. Fear and anticipation of 
pain represent two of the most powerful inhibitors of the sexual response cycle, and the main sources responsible for low desire and lubrication. ${ }^{118-120}$

Based on these premises, reducing pain at intercourse represents the first step in the treatment of women with sexual dysfunctions associated with endometriosis. This goal can be achieved in many cases by the use of hormonal treatment (particularly with long-term low-dose progestin therapy), by surgery, or by other alternative methods previously described (ie, TENS, NAC). However, specific alternative methods can be suggested to women facing painful intercourse, although there is no scientific consensus on this particular issue. For instance, the use of lubrication agents can help women in treating the pain associated with sexual activities (reducing the friction caused by penetration) as a consequence of low lubrication levels due to hypoactive sexual desire.

Dyspareunia can also be treated by modifying sexual technique. For example, increasing the amount of foreplay and delaying penetration can amplify genital lubrication and consequently decrease the pain associated with penetration. Moreover, frequently patients indicate that specific sexual positions are more painful than others. Trying alternative sexual positions may help in reducing pain associated with intercourse, facilitating slow and gentle penetration. In addition, some women find that sexual intimacy is more enjoyable and satisfying at certain times of the month, whereas immediately before or after menstruation sexual intercourse is more painful. Furthermore, besides pain due to pelvic inflammation or anatomical distortion related to endometriosis, psychological dimensions (such as anxiety, depression, and personality traits) or relational mechanisms (feelings, behaviors, relational adjustment) play an important role in sexual functioning. ${ }^{10,120,121}$ Consequently, a comprehensive approach considering all the various aspects of female sexuality should be strongly encouraged.

When sexual difficulties are particularly worrying and distressing, sexual therapy can be very useful, and could represent a rather pleasant experience for the couple. Sexual therapy is a particular therapeutic technique specifically designed to help people facing sexual difficulties, created with the aim of improving their physical intimacy. It is provided by licensed physicians, psychologists, or psychotherapists who have undergone specific training, and provides an outlet for women to disclose and discuss their sexual problems with a supportive specialized professional figure.
Sexual therapists can also suggest relaxation and communication techniques, which could facilitate better physical and emotional relationships. Additionally, women may ask sexual therapists about sensitive issues regarding sexual techniques or alternative sexual practices. Moreover, sexual therapy may facilitate open and honest communication between women and their partners. Further research is needed to confirm the potential beneficial effects of sexual therapy on endometriosis patients and their love life.

\section{Conclusion}

Numerous cofactors can play a role in the progression and maintenance of endometriosis, which is thus a complex multifactorial disease. In this review, we have analyzed the role of several factors (Table 2), such as diet and physical exercise. In both cases, scientific data are scarce and inconsistent. Moreover, the adjuvant effect of CAM is difficult to interpret, because most of the available evidence was derived from nonrandomized uncontrolled trials, case reports, or case series, which are subject to many sources of bias. High-quality studies are needed, in order to evaluate the real effectiveness of the different CAM approaches in the treatment of symptomatic endometriosis.

Hormonal therapy represents the treatment of choice in patients with endometriosis; with this in mind, we could consider CAM a supplementary option to be added to hormonal treatment, or as a valuable opportunity for those women in whom medical therapy is contraindicated. In particular, some interventions, such as the introduction of a gluten-free diet and regular physical exercise, may have a beneficial impact on symptoms related to the disease. On the other hand, other practices, including CHM, NAC, and resveratrol, have been proposed as alternative treatments for endometriosis. Encouraging results have been found on mouse models with dietary supplements, such as resveratrol and NAC. However, further studies are needed on human subjects, in order to evaluate their role in the treatment of the disease.

Finally, the importance of a multidisciplinary team, including an expert sexual therapist and a psychologist, appears crucial in order to deal adequately with all the multifaceted repercussions that women with endometriosis often experience, but may be reluctant to describe and address. In this regard, the approach to every woman with endometriosis should be individualized, proposing the best treatment options based on the different symptoms and problems distressing the patient, and taking into account her preferences and priorities. 
Table 2 Summary of modifiable factors and complementary alternative factors associated with endometriosis

\begin{tabular}{|c|c|c|}
\hline Intervention & Processes potentially involved & Effect on the disease \\
\hline \multicolumn{3}{|l|}{ Diet } \\
\hline - Fish, $\omega 3$ PUFAs & $\begin{array}{l}\text { Anti-inflammatory profile and reduce proinflammatory } \\
\text { prostaglandin production and cytokines }\end{array}$ & Debated $\downarrow$ \\
\hline - Red meat & $\begin{array}{l}\text { High amount of fat ( } \omega 6 \mathrm{FAs} \text { ) involved in the production of } \\
\text { proinflammatory prostaglandins; increased plasma concentration of } \\
\text { estradiol and estrogen-mediated disease maintenance }\end{array}$ & Debated $\uparrow$ \\
\hline - Fruit and vegetables & $\begin{array}{l}\text { Antioxidant properties; potential beneficial effects counterbalanced } \\
\text { by large use of pesticides and dioxins in cultivation process }\end{array}$ & Debated \\
\hline - Coffee & $\begin{array}{l}\text { Aromatase inhibitor; ability to act on SHBG, reducing the } \\
\text { bioavailability of testosterone }\end{array}$ & No association \\
\hline - Gluten-free diet & $\begin{array}{l}\text { Avoids the consumption of gluten, a nutrient with proinflammatory } \\
\text { properties }\end{array}$ & $\begin{array}{l}\text { Improvement in pain } \\
\text { symptoms }\end{array}$ \\
\hline Physical activity & $\begin{array}{l}\text { Reduction in estrogen levels and frequency of ovulation (when } \\
\text { performed at high levels of intensity); increase of SHBG levels with } \\
\text { a subsequent reduction of bioavailable estrogens; reduction of } \\
\text { insulin resistance and hyperinsulinemia }\end{array}$ & Debated $\downarrow$ \\
\hline Osteopathy and massage & $\begin{array}{l}\text { Improvement of musculoskeletal symptoms could reduce } \\
\text { inflammation of internal organs }\end{array}$ & $\begin{array}{l}\text { Improvement in pain symptoms } \\
\text { (low level of evidence) }\end{array}$ \\
\hline Acupuncture & $\begin{array}{l}\text { Release of endogenous opioids, anti-inflammatory systemic } \\
\text { effect, deactivation of brain areas linked to the transmission } \\
\text { of pain sensations, and intensification of local blood flow at } \\
\text { needle-insertion site }\end{array}$ & $\begin{array}{l}\text { Improvement in pain symptoms } \\
\text { (low level of evidence due to } \\
\text { small sample sizes) }\end{array}$ \\
\hline Chinese herbal medicine & $\begin{array}{l}\text { Anti-inflammatory activity; on animal model, suppression of } \\
\text { endometriotic implants }\end{array}$ & $\begin{array}{l}\text { Debated (limited quality } \\
\text { of data) }\end{array}$ \\
\hline \multicolumn{3}{|l|}{ Vitamins } \\
\hline - Vitamin D & $\begin{array}{l}\text { Antiproliferative, anti-inflammatory, and immunomodulatory } \\
\text { properties }\end{array}$ & Debated \\
\hline - Vitamin $A$, vitamin $C$, and $\beta$-carotene & $\begin{array}{l}\text { Antioxidant properties; involved in the production of ROS and cell } \\
\text { proliferation }\end{array}$ & Debated \\
\hline $\mathrm{N}$-acetylcysteine & $\begin{array}{l}\text { Reduction in the release of proinflammatory cytokines; reduction } \\
\text { of cell proliferation and downregulation of the inflammatory } \\
\text { cascade }\end{array}$ & $\begin{array}{l}\text { Improvement in pain } \\
\text { symptoms and reduction of } \\
\text { ovarian endometrioma-lesion } \\
\text { size }\end{array}$ \\
\hline Resveratrol & Antiangiogenic, anti-inflammatory, and antioxidant properties & $\begin{array}{l}\text { Reduction in the number } \\
\text { and volume of endometriotic } \\
\text { lesions (experimental studies) }\end{array}$ \\
\hline $\begin{array}{l}\text { Endocrine disruptors (ie, dioxin, } \\
\text { dioxin-like compounds, and bisphenol A) }\end{array}$ & Alteration of hormone synthesis and receptor activity & Debated $\uparrow$ \\
\hline
\end{tabular}

Note: Arrows indicate risk direction.

Abbreviations: FAs, fatty acids; PUFAs, polyunsaturated fatty acids; ROS, reactive oxygen species; SHBG, sex hormone binding globulin.

\section{Acknowledgment}

This article was financed by Italian fiscal contribution “5×1,000” - Ministero dell'Istruzione, dell'Università e della Ricerca - devolved to Fondazione Istituto di Ricovero e Cura a Carattere Scientifico Ca' Granda Ospedale Maggiore Policlinico, Milan, Italy.

\section{Disclosure}

The authors report no conflicts of interest in this work.

\section{References}

1. Vercellini P, Buggio L, Berlanda N, Barbara G, Somigliana E, Bosari S. Estrogen-progestins and progestins for the management of endometriosis. Fertil Steril. 2016;106(7):1552-1571.e2.
2. Burney RO, Giudice LC. Pathogenesis and pathophysiology of endometriosis. Fertil Steril. 2012;98(3):511-519.

3. Vercellini P. Endometriosis: what a pain it is. Semin Reprod Endocrinol. 1997;15(3):251-261.

4. Vercellini P, Viganò P, Somigliana E, Fedele L. Endometriosis: pathogenesis and treatment. Nat Rev Endocrinol. 2014;10(5):261-275.

5. Viganò P, Parazzini F, Somigliana E, Vercellini P. Endometriosis: epidemiology and aetiological factors. Best Pract Res Clin Obstet Gynaecol. 2004;18(2):177-200.

6. Kong S, Zhang YH, Liu CF, et al. The complementary and alternative medicine for endometriosis: a review of utilization and mechanism. Evid Based Complement Alternat Med. 2014;2014:146383.

7. Facchin F, Barbara G, Saita E, et al. Impact of endometriosis on quality of life and mental health: pelvic pain makes the difference. J Psychosom Obstet Gynaecol. 2015;36(4):135-141.

8. Parazzini F, Viganò P, Candiani M, Fedele L. Diet and endometriosis risk: a literature review. Reprod Biomed Online. 2013;26(4): 323-336. 
9. Missmer SA, Chavarro JE, Malspeis S, et al. A prospective study of dietary fat consumption and endometriosis risk. Hum Reprod. 2010; 25(6):1528-1535.

10. Gerhard I, Runnebaum B. [The limits of hormone substitution in pollutant exposure and fertility disorders]. Zentralbl Gynakol. 1992; 114(12):593-602. German.

11. Halpern G, Schor E, Kopelman A. Nutritional aspects related to endometriosis. Rev Assoc Med Bras (1992). 2015;61(6):519-523.

12. Netsu S, Konno R, Odagiri K, Soma M, Fujiwara H, Suzuki M. Oral eicosapentaenoic acid supplementation as possible therapy for endometriosis. Fertil Steril. 2008;90(4 Suppl):1496-1502.

13. Khanaki K, Nouri M, Ardekani AM, et al. Evaluation of the relationship between endometriosis and omega- 3 and omega- 6 polyunsaturated fatty acids. Iran Biomed J. 2012;16(1):38-43.

14. Savaris AL, do Amaral VF. Nutrient intake, anthropometric data and correlations with the systemic antioxidant capacity of women with pelvic endometriosis. Eur J Obstet Gynecol Reprod Biol. 2011;158(2): 314-318.

15. Heilier JF, Donnez J, Nackers F, et al. Environmental and host-associated risk factors in endometriosis and deep endometriotic nodules: a matched case-control study. Environ Res. 2007;103(1):121-129.

16. Trabert B, Peters U, De Roos AJ, Scholes D, Holt VL. Diet and risk of endometriosis in a population-based case-control study. Br J Nutr. 2011; 105(3):459-467.

17. Parazzini F, Chiaffarino F, Surace M, et al. Selected food intake and risk of endometriosis. Hum Reprod. 2004;19(8):1755-1759.

18. Chiaffarino F, Bravi F, Cipriani S, et al. Coffee and caffeine intake and risk of endometriosis: a meta-analysis. Eur J Nutr. 2014;53(7): 1573-1579.

19. Ferrini RL, Barrett-Connor E. Caffeine intake and endogenous sex steroid levels in postmenopausal women: the Rancho Bernardo study Am J Epidemiol. 1996;144(7):642-644.

20. Kotsopoulos J, Eliassen AH, Missmer SA, Hankinson SE, Tworoger SS. Relationship between caffeine intake and plasma sex hormone concentrations in premenopausal and postmenopausal women. Cancer. 2009;115(12):2765-2774.

21. Wedick NM, Mantzoros CS, Ding EL, et al. The effects of caffeinated and decaffeinated coffee on sex hormone-binding globulin and endogenous sex hormone levels: a randomized controlled trial. Nutr J. 2012;11:86.

22. Marziali M, Venza M, Lazzaro S, Lazzaro A, Micossi C, Stolfi VM. Gluten-free diet: a new strategy for management of painful endometriosis related symptoms? Minerva Chir. 2012;67(6):499-504.

23. Marziali M, Capozzolo T. Role of gluten-free diet in the management of chronic pelvic pain of deep infiltranting [sic] endometriosis. J Minim Invasive Gynecol. 2015;22(6S):S51-S52.

24. Demarzo MM, Martins LV, Fernandes CR, et al. Exercise reduces inflammation and cell proliferation in rat colon carcinogenesis. Med Sci Sport Exerc. 2008;40(4):618-621.

25. Thune I, Furberg AS. Physical activity and cancer risk: dose-response and cancer, all sites and site-specific. Med Sci Sports Exerc. 2001; 33(6 Suppl):S530-S550.

26. Cheifetz AS, Gianotti R, Luber R, Gibson PR. Complementary and alternative medicines used by patients with inflammatory bowel diseases. Gastroenterology. 2017;152(2):415-429.e15.

27. Ricci E, Viganò P, Cipriani S, et al. Physical activity and endometriosis risk in women with infertility or pain: systematic review and metaanalysis. Medicine (Baltimore). 2016;95(40):e4957.

28. Friberg E, Wallin A, Wolk A. Sucrose, high-sugar foods, and risk of endometrial cancer: a population-based cohort study. Cancer Epidemiol Biomarkers Prev. 2011;20(9):1831-1837.

29. Colditz GA, Cannuscio CC, Frazier AL. Physical activity and reduced risk of colon cancer: implications for prevention. Cancer Causes Control. 1997;8(4):649-667.

30. Wu MH, Shoji Y, Chuang PC, Tsai SJ. Endometriosis: disease pathophysiology and the role of prostaglandins. Expert Rev Mol Med. 2007;9(2):1-20.
31. Rosa-e-Silva JC, Montenegro ML, Meola J, Zani AC, Ferriani RA. Influence of physical exercise on endometriosis experimentally induced in rats. J Minim Invasive Gynecol. 2015;22(6S):S167.

32. Gonçalves AV, Makuch MY, Setubal MS, Barros NF, Bahamondes L. A qualitative study on the practice of yoga for women with pain-associated endometriosis. J Altern Complement Med. 2016;22(12):977-982.

33. World Health Organization. WHO Traditional Medicine Strategy 2002-2005. Geneva: WHO; 2002.

34. Raub JA. Psychophysiologic effects of hatha yoga on musculoskeletal and cardiopulmonary function: a literature review. J Altern Complement Med. 2002;8(6):797-812.

35. Manocha R, Marks GB, Kenchington P, Peters D, Salome CM. Sahaja yoga in the management of moderate to severe asthma: a randomised controlled trial. Thorax. 2002;57(2):110-115.

36. Oken BS, Kishiyama S, Zajdel D, et al. Randomized controlled trial of yoga and exercise in multiple sclerosis. Neurology. 2004; 62(11):2058-2064.

37. World Health Organization. General guidelines for methodologies on research and evaluation of traditional medicine. 2000. Available from: http://apps.who.int/iris/bitstream/10665/66783/1/WHO_EDM_ TRM_2000.1.pdf. Accessed December 26, 2016.

38. Fisher C, Adams J, Hickman L, Sibbritt D. The use of complementary and alternative medicine by 7427 Australian women with cyclic perimenstrual pain and discomfort: a cross-sectional study. BMC Complement Altern Med. 2016;16:129.

39. World Health Organization. Benchmarks for Training in Traditional/ Complementary and Alternative Medicine. Geneva: WHO; 2010.

40. Herbert B. Chronic pelvic pain. Altern Ther Health Med. 2010; 16(1):28-33.

41. Vismara L, Cimolin V, Menegoni F, et al. Osteopathic manipulative treatment in obese patients with chronic low back pain: a pilot study. Man Ther. 2012;17(5):451-455.

42. Sillem M, Juhasz-Böss I, Klausmeier I, Mechsner S, Siedentopf F, Solomayer E. Osteopathy for endometriosis and chronic pelvic pain: a pilot study. Geburtshilfe Frauenheilkd. 2016;76(9):960-963.

43. Darai C, Deboute O, Zacharopoulou C, et al. Impact of osteopathic manipulative therapy on quality of life of patients with deep infiltrating endometriosis with colorectal involvement: results of a pilot study. Eur J Obstet Gynecol Reprod Biol. 2015;188:70-73.

44. Valiani M, Ghasemi N, Bahadoran P, Heshmat R. The effects of massage therapy on dysmenorrhea caused by endometriosis. Iran J Nurs Midwifery Res. 2010;15(4):167-171.

45. Berman BM, Langevin HM, Witt CM, Dubner R. Acupuncture for chronic low back pain. $N$ Engl J Med. 2010;363(5):454-461.

46. Lund I, Lundeberg $\mathrm{T}$. Is acupuncture effective in the treatment of pain in endometriosis? J Pain Res. 2016;9:157-165.

47. Vickers AJ, Linde K. Acupuncture for chronic pain. JAMA. 2014; 311(9):955-956.

48. Smith CA, Armour M, Zhu X, Li X, Lu ZY, Song J. Acupuncture for dysmenorrhoea. Cochrane Database Syst Rev. 2016;4:CD007854.

49. Highfield ES, Laufer MR, Schnyer RN, Kerr CE, Thomas P, Wayne PM. Adolescent endometriosis-related pelvic pain treated with acupuncture: two case reports. J Altern Complement Med. 2006;12(3): 317-322.

50. Wayne PM, Kerr CE, Schnyer RN, et al. Japanese-style acupuncture for endometriosis-related pelvic pain in adolescents and young women: results of a randomized sham-controlled trial. J Pediatr Adolesc Gynecol. 2008;21(5):247-257.

51. Rubi-Klein K, Kucera-Sliutz E, Nissel H, et al. Is acupuncture in addition to conventional medicine effective as pain treatment for endometriosis? A randomised controlled cross-over trial. Eur J Obstet Gynecol Reprod Biol. 2010;153(1):90-93.

52. Johnson MI, Jones G. Transcutaneous electrical nerve stimulation: current status of evidence. Pain Manag. 2017;7(1):1-4.

53. Mira TA, Giraldo PC, Yela DA, Benetti-Pinto CL. Effectiveness of complementary pain treatment for women with deep endometriosis through transcutaneous electrical nerve stimulation (TENS): randomized controlled trial. Eur J Obstet Gynecol Reprod Biol. 2015;194:1-6. 
54. Proctor M, Farquhar C, Stones W, He L, Zhu X, Brown J. Transcutaneous electrical nerve stimulation for primary dysmenorrhoea. Cochrane Database Syst Rev. 2002;(1):CD002123.

55. Johnson NP, Hummelshoj L. Consensus on current management of endometriosis. Hum Reprod. 2013;28(6):1552-1568.

56. Wieser F, Yu J, Park J, et al. A botanical extract from channel flow inhibits cell proliferation, induces apoptosis, and suppresses CCL5 in human endometriotic stromal cells. Biol Reprod. 2009;81(2):371-377.

57. Rocha AL, Reis FM, Petraglia F. New trends for the medical treatment of endometriosis. Expert Opin Investig Drugs. 2012;21(7):905-919.

58. Flower A, Liu PJ, Lewith G, Little P, Li Q. Chinese herbal medicine for endometriosis. Cochrane Database Syst Rev. 2012;(5):CD006568.

59. Wu SZ, Chen XL, Chen WZ, Li S. Clinical analysis of the treatment of endometriosis using nei yi pills and nei yi enema. J Liaoning Univ TCM. 2006;8(7):5-6.

60. Wu S, Chen X, Huang Y. [Observation on effect of combined therapy of neiyi pill and neiyi enema on endometriosis]. Chinese Journal of Integrated Traditional and Western Medicine. 2006;26(6):557-559.

61. Zhu S, Liu D, Huang W, et al. Post-laparoscopic oral contraceptive combined with Chinese herbal mixture in treatment of infertility and pain associated with minimal or mild endometriosis: a randomized controlled trial. BMC Complement Altern Med. 2014;14:222.

62. NHS Choices. [webpage on the Internet]. Vitamins and minerals. Available at http://www.nhs.uk/Conditions/vitamins-minerals/Pages/ vitamins-minerals.aspx. Accessed April 13, 2017.

63. Buggio L, Roncella E, Somigliana E, Vercellini P. Vitamin D and benign gynaecological diseases: a critical analysis of the current evidence. Gynecol Endocrinol. 2016;32(4):259-263.

64. Lasco A, Catalano A, Benvenga S. Improvement of primary dysmenorrhea caused by a single oral dose of vitamin D: results of a randomized, double-blind, placebo-controlled study. Arch Intern Med. 2012; 172(4):366-367.

65. Mariani M, Vigano P, Gentilini D, et al. The selective vitamin D receptor agonist, elocalcitol, reduces endometriosis development in a mouse model by inhibiting peritoneal inflammation. Hum Reprod. 2012;27(7):2010-2019.

66. Miyashita M, Koga K, Izumi G, et al. Effects of 1,25-dihydroxy vitamin D3 on endometriosis. J Clin Endocrinol Metab. 2016;101(6): 2371-2379.

67. Almassinokiani F, Khodaverdi S, Solaymani-Dodaran M, Akbari P, Pazouki A. Effects of vitamin D on endometriosis-related pain: a doubleblind clinical trial. Med Sci Monit. 2016;22:4960-4966.

68. Hartwell D, Rødbro P, Jensen SB, Thomsen K, Christiansen C. Vitamin D metabolites: relation to age, menopause and endometriosis. Scand J Clin Lab Invest. 1990;50(2):115-121.

69. Somigliana E, Panina-Bordignon P, Murone S, Di Lucia P, Vercellini P, Vigano P. Vitamin D reserve is higher in women with endometriosis. Hum Reprod. 2007;22(8):2273-2278.

70. Agic A, Xu H, Altgassen C, et al. Relative expression of 1,25dihydroxyvitamin D3 receptor, vitamin D $1 \alpha$-hydroxylase, vitamin D 24-hydroxylase, and vitamin D 25-hydroxylase in endometriosis and gynecologic cancers. Reprod Sci. 2007;14(5):486- 497.

71. Harris HR, Chavarro JE, Malspeis S, Willett WC, Missmer SA. Dairyfood, calcium, magnesium, and vitamin $\mathrm{D}$ intake and endometriosis: a prospective cohort study. Am J Epidemiol. 2013;177(5):420-430.

72. Ciavattini A, Serri M, Delli Carpini G, Morini S, Clemente N. Ovarian endometriosis and vitamin D serum levels. Gynecol Endocrinol. 2017; 33(2):164-167.

73. Mier-Cabrera J, Jimenez-Zamudio L, Garcia-Latorre E, Cruz-Orozco O, Hernandez-Guerrero C. Quantitative and qualitative peritoneal immune profiles, T-cell apoptosis and oxidative stress-associated characteristics in women with minimal and mild endometriosis. BJOG. 2011; 118(1):6-16.

74. Sesti F, Capozzolo T, Pietropolli A, Marziali M, Bollea MR, Piccione E. Recurrence rate of endometrioma after laparoscopic cystectomy: a comparative randomized trial between post-operative hormonal suppression treatment or dietary therapy vs. placebo. Eur JObstet Gynecol Reprod Biol. 2009;147(1):72-77.
75. Elbini-Dhouib I, Jallouli M, Annabi A, Gharbi N, Elfazaa S, Lasram MM. A minireview on N-acetylcysteine: an old drug with new approaches. Life Sci. 2016;151:359-363.

76. Porpora MG, Brunelli R, Costa G, et al. A promise in the treatment of endometriosis: an observational cohort study on ovarian endometrioma reduction by N-acetylcysteine. Evid Based Complement Alternat Med. 2013;2013:240702.

77. Wolfe I. Food sources of N-acetyl cysteine. 2014. Available from: http:// www.livestrong.com/article/531520-food-sources-of-n-acetyl-cysteine. Accessed December 27, 2016.

78. Pittaluga E, Costa G, Krasnowska E, et al. More than antioxidant: $\mathrm{N}$-acetyl-L-cysteine in a murine model of endometriosis. Fertil Steril. 2010;94(7):2905-2908.

79. Cucciolla V, Borriello A, Oliva A, Galletti P, Zappia V, Della Ragione F. Resveratrol: from basic science to the clinic. Cell Cycle. 2007;6(20): 2495-2510.

80. Yu W, Fu YC, Wang W. Cellular and molecular effects of resveratrol in health and disease. $J$ Cell Biochem. 2012;11(3):752-759.

81. Markus MA, Morris BJ. Resveratrol in prevention and treatment of common clinical conditions of aging. Clin Interv Aging. 2008;3(2): 331-339.

82. Bruner-Tran KL, Osteen KG, Taylor HS, Sokalska A, Haines K, Duleba AJ. Resveratrol inhibits development of experimental endometriosis in vivo and reduces endometrial stromal cell invasiveness in vitro. Biol Reprod. 2011;84(1):106-112.

83. Ricci AG, Olivares CN, Bilotas MA, et al. Natural therapies assessment for the treatment of endometriosis. Hum Reprod. 2013;28(1): $178-188$.

84. Rudzitis-Auth J, Menger MD, Laschke MW. Resveratrol is a potent inhibitor of vascularization and cell proliferation in experimental endometriosis. Hum Reprod. 2013;28(5):1339-1347.

85. Tekin YB, Guven S, Kirbas A, Kalkan Y, Tumkaya L, Guven ES. Is resveratrol a potential substitute for leuprolide acetate in experimental endometriosis? Eur J Obstet Gynecol Reprod Biol. 2015;184:1-6.

86. Zoeller RT, Brown TR, Doan LL, et al. Endocrine-disrupting chemicals and public health protection: a statement of principles from the Endocrine Society. Endocrinology. 2012;153(9):4097-4110.

87. Smarr MM, Kannan K, Louis GM. Endocrine disrupting chemicals and endometriosis. Fertil Steril. 2016;106(4):959-966.

88. Soave I, Caserta D, Wenger JM, Dessole S, Perino A, Marci R. Environment and endometriosis: a toxic relationship. Eur Med Pharmacol Sci. 2015;19(11):1964-1972.

89. Van den Berg M, Birbaum LS, Denison M, et al. The 2005 World Health Organization reevaluation of human and mammalian toxic equivalency factors for dioxins and dioxin-like compounds. Toxicol Sci. 2006;93(2):223-241.

90. Rier SE, Martin DC, Bowman RE, Dmowski WP, Becker JL. Endometriosis in rhesus monkeys (Macaca mulatta) following chronic exposure to 2,3,7,8-tetrachlorodibenzo-p-dioxin. Fundam Appl Toxicol. 1993;21(4):433-341.

91. Rier SE, Turner WE, Martin DC, Morris R, Lucier GW, Clark GC. Serum levels of TCDD and dioxin-like chemicals in rhesus monkeys chronically exposed to dioxin: correlation of increased serum PCB levels with endometriosis. Toxicol Sci. 2001;59(1):147-159.

92. Bredhult C, Bäcklin BM, Olovsson M. Effects of some endocrine disruptors on the proliferation and viability of human endometrial endothelial cells in vitro. Reprod Toxicol. 2007;23(4):550-559.

93. Eskenazi B, Mocarelli P, Warner M, et al. Serum dioxin concentrations and endometriosis: a cohort study in Seveso, Italy. Environ Health Perspect. 2002;110(7):629-634.

94. Heilier JF, Nackers F, Verougstraete V, Tonglet R, Lison D, Donnez J. Increased dioxin-like compounds in the serum of women with peritoneal endometriosis and deep endometriotic (adenomyotic) nodules. Fertil Steril. 2005;84(2):305-312.

95. Porpora MG, Medda E, Abballe A, et al. Endometriosis and organochlorinated environmental pollutants: a case-control study on Italian women of reproductive age. Environ Health Perspect. 2009; 117(7):1070-1075. 
96. Caserta D, Mantovani A, Marci R, et al. Environment and women's reproductive health. Hum Reprod Update. 2011;17(3):418-433.

97. Caserta D, Di Segni N, Mallozzi M, et al. Bisphenol A and the female reproductive tract: an overview of recent laboratory evidence and epidemiological studies. Reprod Biol Endocrinol. 2014;12:37.

98. Ehrlich S, Williams PL, Missmer SA, et al. Urinary bisphenol A concentrations and early reproductive health outcomes among women undergoing IVF. Hum Reprod. 2012;27(12):3583-3592.

99. Caserta D, Ciardo F, Bordi G, et al. Correlation of endocrine disrupting chemicals serum levels and white blood cells gene expression of nuclear receptors in a population of infertile women. Int J Endocrinol. 2013;2013:510703.

100. Cobellis L, Colacurci N, Trabucco E, Carpentiero C, Grumetto L. Measurement of bisphenol A and bisphenol B levels in human blood sera from healthy and endometriotic women. Biomed Chromatogr. 2009;23(11):1186-1190.

101. Buck Louis GM, Peterson CM, Chen Z, et al. Bisphenol A and phthalates and endometriosis: the Endometriosis: Natural History, Diagnosis and Outcomes Study. Fertil Steril. 2013;100(1):162-169.e1-e2.

102. Itoh H, Iwasaki M, Hanaoka T, Sasaki H, Tanaka T, Tsugane S. Urinary bisphenol-A concentration in infertile Japanese women and its association with endometriosis: a cross-sectional study. Environ Health Prev Med. 2007;12(6):258-264.

103. Signorile PG, Spugnini EP, Mita L, et al. Pre-natal exposure of mice to bisphenol A elicits an endometriosis-like phenotype in female offspring. Gen Comp Endocrinol. 2010;168(3):318-325.

104. Denny E. I never know from one day to another how I will feel: pain and uncertainty in women with endometriosis. Qual Health Res. 2009;19(7):985-995.

105. Moradi M, Parker M, Sneddon A, Lopez V, Ellwood D. Impact of endometriosis on women's lives: a qualitative study. BMC Womens Health. 2014;14:123.

106. Meissner K, Schweizer-Arau A, Limmer A, et al. Psychotherapy with somatosensory stimulation for endometriosis-associated pain: a randomized controlled trial. Obstet Gynecol. 2016;128(5): $1134-1142$.

107. Hansen KE, Kesmodel US, Kold M, Forman A. Long-term effects of mindfulness-based psychological intervention for coping with pain in endometriosis: a six-year follow-up on a pilot study. Nord Psychol. 2017;69(2):100-109.

108. Kold M, Hansen T, Vedsted-Hansen H, Forman A. Mindfulness-based psychological intervention for coping with pain in endometriosis. Nord Psychol. 2012;64(1):2-16.
109. Facchin F, Saita E, Barbara G, Dridi D, Vercellini P. "Free butterflies will come out of these deep wounds": a grounded theory of how endometriosis affects women's psychological health. J Health Psychol. Epub 2017 Jan 11.

110. Facchin F, Barbara G, Saita E, et al. Personality in women with endometriosis: temperament and character dimensions and pelvic pain. Hum Reprod. 2016;31(7):1515-1521.

111. Barbara G, Facchin F, Meschia M, Berlanda N, Frattaruolo MP, Vercellini P. When love hurts: a systematic review on the effects of endometriosis surgical and pharmacological treatments on female sexual functioning. Acta Obstet Gynecol Scand. Epub 2016 Sep 30.

112. Vercellini P, Somigliana E, Consonni D, Frattaruolo MP, De Giorgi O, Fedele L. Surgical versus medical treatment for endometriosis-associated severe deep dyspareunia - I: effect on pain during intercourse and patient satisfaction. Hum Reprod. 2012;27(12): $3450-3459$.

113. Vercellini P, Aimi G, Busacca M, Apolone G, Uglietti A, Crosignani PG. Laparoscopic uterosacral ligament resection for dysmenorrhea associated with endometriosis: results of a randomized, controlled trial. Fertil Steril. 2003;80(2):310-319.

114. Meana M, Binik YM, Khalife S, Cohen DR. Biopsychosocial profile of women with dyspareunia. Obstet Gynecol. 1997;90(4 Pt 1): 583-589.

115. Ferrero S, Ragni N, Remorgida V. Deep dyspareunia: causes, treatments, and results. Curr Opin Obstet Gynecol. 2008;20(4):394-399.

116. Fenigstein A, Scheier MF, Buss AH. Public and private selfconsciousness: assessment and theory. J Consult Clin Psychol. 1975; 43(4):522-527.

117. Buster JE. Managing female sexual dysfunction. Fertil Steril. 2013;100(4):905-915.

118. Di Donato N, Montanari G, Benfenati A, et al. Do women with endometriosis have to worry about sex? Eur J Obstet Gynecol Reprod Biol. 2014;179:69-74.

119. Fritzer N, Haas D, Oppelt P, et al. More than just bad sex: sexual dysfunction and distress in patients with endometriosis. Eur J Obstet Gynecol Reprod Biol. 2013;169(2):392-396.

120. Ferrero S, Esposito F, Abbamonte LH, Anserini P, Remorgida V, Ragni N. Quality of sex life in women with endometriosis and deep dyspareunia. Fertil Steril. 2005;83(3):573-579.

121. Rosen RC, Riley A, Wagner G, Osterloh IH, Kirkpatrick J, Mishra A. The international index of erectile function (IIEF) a multidimensional scale for assessment of erectile dysfunction. Urology. 1997;49(6):822-830.
International Journal of Women's Health

\section{Publish your work in this journal}

The International Journal of Women's Health is an international, peerreviewed open-access journal publishing original research, reports, editorials, reviews and commentaries on all aspects of women's healthcare including gynecology, obstetrics, and breast cancer. The manuscript management system is completely online and includes

\section{Dovepress}

a very quick and fair peer-review system, which is all easy to use. Visit http://www.dovepress.com/testimonials.php to read real quotes from published authors. 